\title{
WestVirginiaUniversity
}

THE RESEARCH REPOSITORY @ WVU

Graduate Theses, Dissertations, and Problem Reports

2002

\section{Interpersonal conflict within the context of the organization}

Jodi Lynn Sauders

West Virginia University

Follow this and additional works at: https://researchrepository.wvu.edu/etd

\section{Recommended Citation}

Sauders, Jodi Lynn, "Interpersonal conflict within the context of the organization" (2002). Graduate Theses, Dissertations, and Problem Reports. 840.

https://researchrepository.wvu.edu/etd/840

This Thesis is protected by copyright and/or related rights. It has been brought to you by the The Research Repository @ WVU with permission from the rights-holder(s). You are free to use this Thesis in any way that is permitted by the copyright and related rights legislation that applies to your use. For other uses you must obtain permission from the rights-holder(s) directly, unless additional rights are indicated by a Creative Commons license in the record and/ or on the work itself. This Thesis has been accepted for inclusion in WVU Graduate Theses, Dissertations, and Problem Reports collection by an authorized administrator of The Research Repository @ WVU. For more information, please contact researchrepository@mail.wvu.edu. 
Interpersonal Conflict Within the Context of the Organization

\author{
Jodi Sauders
}

Thesis submitted to the Eberly College of Arts and Sciences at West Virginia University in partial fulfillment of the requirements for the degree of

\author{
Master of Arts \\ in \\ Communication Studies \\ Keith D. Weber, Ph.D., Chair \\ Brian R. Patterson, Ph.D. \\ Rebecca M. Chory-Assad, Ph.D. \\ Department of Communication Studies \\ Morgantown, West Virginia \\ 2002
}

Keywords: Conflict, Organizational Conflict, Interpersonal Conflict, Extraversion,

Neuroticism, Psychoticism 


\section{ABSTRACT \\ Interpersonal conflict within the context of the organization \\ Jodi Sauders}

This investigation was concerned with individual conflict management styles and situations. Participants were asked to complete the Organizational Communication Conflict Instrument (OCCI) (Putnam \& Wilson, 1982) based on a particular conflict with a friend who is not a co-worker and a friend who is a co-worker. Results found that individuals do not change their conflict management styles based on situations. Also considered were the Big Three (Eysenck \& Eysenck, 1985) personality types and their relationship to variability in one's conflict management styles. There were no relationships between variability and the Big Three. 


\section{TABLE OF CONTENTS}

ABSTRACT ii

TABLE OF CONTENTS

ACKNOWLEDGMENTS

CHAPTER 1

INTRODUCTION

Conflict in Contexts

Interpersonal Conflict

Interpersonal Conflict in the Organization

Hypotheses and Research Questions

CHAPTER 2

11

Methods

Participants

Instruments

Data Analysis

CHAPTER 3

14

Results

CHAPTER 4

16

Discussion

$\begin{array}{ll}\text { REFERENCES } & 21\end{array}$

$\begin{array}{ll}\text { TABLE } 1 & 25\end{array}$

$\begin{array}{ll}\text { TABLE } 2 & 26\end{array}$

$\begin{array}{ll}\text { TABLE } 3 & 27\end{array}$ 


\section{ACKNOWLEDGEMENTS}

I would like to give praise in honor to God, my Lord, who has enabled me the ability to succeed in many of my goals in life, including finishing this thesis. Without his strength I would have given up before the completion of the Lit. Review.

I also acknowledge that I would not have been able to complete this without the help of my love, John, and my wonderful family (Mom, Dad, Scott, and Rachel). I love you all and thank you for everything that you have helped me with in completing my Master's degree.

Thanks also to Keith, you rocked! And to the class of 2002, you made this year truly a wonderful and interesting experience! 


\section{Chapter 1}

Conflict in interpersonal and organizational contexts

Conflict occurs when individuals or parties feel they have contrary goals or outcomes (Jameson, 1999). Oetzel, Ting-Toomey, Yokochi, Masumoto, and Takai (2000) describe conflict as a situation between two or more parties based on substantive or relational issues over differences in values, outcomes, or processes, whether real or alleged. Previous research has found that the relational consequences associated with conflict can be positive or negative.

Whether the consequences of a conflict situation are positive or negative, the consequences are determined by the characteristics of the conflict, desired outcomes of the participants, and awareness of conflict management strategies (Jameson, 1999). Aggressive behavior along side of impolite manners increases hostility in conflict situations (Ohbuchi \& Fukushima, 1997). Obliging is viewed, by superiors, as the from a superior from a subordinate in a healthy organization (Rahim, Garret, \& Buntzman, 1992). In opposition to the negative findings associated with conflict, Thomas (1976) asserts that conflict can be beneficial because it aids in the stimulation and the curiosity of the mind.

The key to understanding the mixed findings concerning the potential effects of conflict appears to be the manner in which the conflict is considered. Millar, Rogers, and Bavelas (1984) assert there are two different models to consider when examining conflict: normative and dynamic. Normative models view conflict as problematic and requiring elimination, whereas dynamic models regard conflict as natural and beneficial for the changing dynamics of a relationship. 
The perception of whether a conflict is positive or negative is also a result of the culture in which the conflict takes place. High context cultures do not divide the individual from the situation and would follow a normative model, viewing conflict as being problematic. Low-context cultures encourage a separation between the individual and the conflict issues and would follow a dynamic model, viewing conflict as natural (Chua \& Gudykunst, 1987).

The purpose of this study is to examine conflict styles and contexts. Conflict within the organization is assumed to take place in a high context culture because of the support found in membership, culture, and roles within an organization (Infante, Myers, \& Buerkel, 1994; Pacanowsky \& Trujillo, 1983). This study will examine the use of individual conflict management styles when engaged in conflict with friends in personal and organizational contexts. Furthermore, the role played by personality traits in the use of conflict management styles across contexts will be considered.

\section{Conflict in Contexts}

According to Pacanowsky and Trujillo (1983), an organization is a high context culture because organizations are based on rituals in which members regularly participate to gain a shared reality. Through these roles members are able to accomplish requirements from the group and maintain accord throughout the organization (Oetzel, 1998; Ting-Toomey, Oetzel, \& Yee-Jung, 2001). Also, organizations develop a specific way of doing and discussing issues, which appear to be natural to the members of the organization.

Through their study of verbal aggression and argumentativeness in the context of work and the family, Infante et al. (1994) lend support to viewing organizations as a high 
context culture. Their findings showed verbal aggression to be used at a higher frequency within a family context than in an organizational conflict. They believed the two contexts differed because the organization is a more regulated and restricted environment where emotional reactions are not appropriate. It is the rules and regulations that are present in the organizational setting, which are absent in more volitional relationships, which restrict our use of emotion in organizational conflict. Within the organizational context there is an abundance of sources that carry power or potential power over individuals. Also, simple social desirability bias has an effect on the participants because individuals are not willing to display verbal aggression in public setting, due to verbal aggression not being socially acceptable. The context can also help determine the roles an individual employee plays. The roles reflect the values, behaviors, and beliefs, indicating that acceptable behavior in one context might not be acceptable in another (Infante et al., 1994). Nicotera (1994) supports this by concluding, results from research on marital conflict is not able to be a generalization for the way one might operate in conflict in an organizational setting.

Knapp, Putman, and Davis (1988) affirmed that even when an individual implements the chosen management tactic, he/she is not the only factor in deciding the specific tactic used. One must also anticipate the other person's reactions to certain methods. Individuals may exhibit a number of conflict management styles and no single strategy is likely to be characteristic of an individual. Each strategy may or may not be appropriate for different conflict situations, so the choice of strategy is dependent on the situation and the other (Putnam \& Wilson, 1982). Moberg (1998) supports the idea that it is not appropriate or effective to implement one style for all conflicts or participants. The 
method should be chosen based on the context of the situation. Balance should be maintained between the parties' personal goals and relational expectations when choosing conflict management styles (Canary \& Spitzberg, 1987). When individuals have the opportunity to choose their conflict management style, they should consider their personal goals because the management method they choose may further or hinder this goal (Putnam, 1988).

Social pressure from ingroups, bystanders or neutral parties, and incentive structure (high/low stakes) are factors that affect conflict behavior or management style (Thomas, 1976). Knapp et al. (1988) explain some scholars support that each individual only uses one conflict management method and each method elicits a certain response. When in reality, according to Knapp et al., different situations and circumstances give rise to multiple methods of achieving one's goals. Indeed, a person can implement several different methods simultaneously. Yet, Canary, Coach, and Serape (2001) claimed that people tend to continue to use one conflict management method. Through studying the conflict patterns of 132 married couples at two separate times, they found consistency in the use of integrative or distributive strategies.

\section{Interpersonal Conflict}

Interpersonal conflict usually arises when one party feels another is trying to prevent his/her goals from being achieved (Antonioni, 1998). Similarly, Ohbuchi and Fukushima (1997) describe interpersonal conflict as an event in which an individual potentially jeopardizes another's goals, wishes, or expectations. Solutions to interpersonal conflict usually require the fulfillment of at least one of the parties wants and needs (Antonioni). Parties rarely fully give in to each other, however, in order to de- 
escalate a conflict situation, the parties will reevaluate their goals (Thomas, 1976). Some researchers view interpersonal conflict as cyclical and constant. Within these cycles, the issue is not always obvious, while at other times, the issue rises to the surface, becoming evident. Others view interpersonal conflict as dynamic, causing change within the relationship through resolution (elimination) of the conflict (Walton, 1987).

One can approach conflict in a number of ways. Rahim et al. (1992) classified the five styles of managing interpersonal conflict as integrating (win-win), obliging (losewin), dominating (win-lose), avoiding (lose-lose), and compromising (no win-no lose). These five conflict styles fall into two general categories. The first being assertive, which is showing concern for self. The second is interest-based or cooperation, which indicates a concern for others or relationship-based. The five styles have a direct connection to the self and the other at different levels. Integrating (high concern for self and other) involves a willingness and openness to new ideas and information in order to develop a solution acceptable to both parties. Obliging (low concern for self/high concern for others) places an emphasis on similarities and downplays any differences. Dominating (high concern for self/low concern for others) requires forceful behavior to win one's position. Avoiding (low concern for self and other) is withdrawing from the situation and is beneficial when costs of confronting the situation outweigh benefits. Compromise (medium concern for self and other) allows both parties to give and take in order to reach a mutually acceptable solution. According to Rahim et al., each style has a purposeful and beneficial use at different times, indicating conflict management styles to be situational.

Through the development of the Organizational Communication Conflict 
Instrument (OCCI) Putnam and Wilson (1982) condensed Rahim's five strategies to three. The OCCI strategies include:

1. Non-confrontation: indirect strategies for handling a conflict; chooses to avoid or withdraw from a disagreement; such communicative behaviors as silence, glossing over differences, concealed feelings (Putnam \& Wilson, 1982, p. 647); 2. Solution-orientation: direct communication about the conflict; collaborating behaviors that aim to find a solution to integrate the needs of both parties; giving in or compromising; and accommodating or smoothing the conflict or confronting the issue (Putnam \& Wilson, 1982, p. 647); and

3. Control: direct communication about the disagreement; arguing persistently for one's position; taking control of the interaction; advocating one's position; and competing to enforce one's views (Putnam \& Wilson, 1982, p. 647).

\section{Interpersonal Conflict in the Organization}

In organizations, interpersonal conflict is prevalent and troublesome for managers (Putnam, 1988). Meyer, Gemmell, and Irving (1997) report that middle managers are spending 25 percent of their time handling conflict. When deciding the most effective method for managing conflict, the conflict itself needs to be evaluated. If a situation is a mere disagreement, then parties may agree to disagree. However, if the situation is a conflict, the issue must be resolved in order to reach effective decisions, accomplish goals, and complete activities (Knapp et al., 1988). In order to increase individual, group, and system-wide effectiveness, organizational conflicts are often managed with a temporary or doable solution, instead of being resolved (Rahim et al., 1992).

Ritov and Drory (1996) found that in organizational conflict, the amount of 
ambiguity surrounding an issue influences the conflict management method initially chosen, and that parties usually do not procrastinate or ignore the issue if there is a high level of ambiguity. Jameson (1999) supports these ideas by claiming that when parties are placed in a completely unfamiliar situation, they wish to resolve the conflict as quickly as possible. Jameson's study found that this desire for conflict resolution is due to the decision-making competence placed on the parties. If they are informed on an issue, they have to claim more responsibility than if they are uninformed. In other words, one of the main reasons a decision maker wants to avoid ambiguity is because of responsibility. In ambiguous conflict situations, management methods of collaboration and compromise are used more often than in unambiguous situations. This allows for more solution ideas to be developed. However, avoiding, accommodating, and forcing methods do not differ in their usage rate whether in ambiguous or unambiguous conflict. Even if there is low ambiguity with the issues of the conflict, there are still many variables to consider (e.g., time, range of impact on the organization, degree of conflict escalation, and management options available) (Jameson).

The conflict management styles used in interpersonal conflicts and organizational conflicts are very similar; however, the rationale for choosing one style over another differs across the contexts. Employees often take a submissive approach toward those who potentially control their future rewards. In this situation, direct competition is usually avoided, solution-oriented approaches are refrained, and a nonconfrontational style is adopted. Obliging is often the expected response of a superior from a subordinate in a healthy organization (Rahim et al., 1992). How workers respond to conflict is learned through past behaviors and their understanding and perception of the internal 
environment of the company (Drory \& Ritov, 1997).

\section{Rationale}

This manuscript has concerned itself with individual conflict management styles when engaged in conflict with friends in personal and organizational contexts. Conflict within the organization takes place in a high context culture because of the support found in membership, culture, rules and roles within an organization, whereas, conflict within one's personal life occurs in a low context culture because relationships of volition are not governed by the same roles and rules (Infante et al., 1994; Pacanowsky \& Trujillo, 1983).

Based on Oetzel et al. (2000), people who are members of a low context culture exhibit a dominating (controlling) conflict style. Meanwhile, Infante et al. (1994) found that verbal aggression is more prominent in the context of the family than in the workplace. Therefore, the following hypothesis is proposed:

H1: Individuals will more frequently use the controlling style of conflict management in their personal lives than they will in their organization(s).

Individuals in high-context cultures tend to use indirect, implicit, and ambiguous communication resulting in nonconfrontational styles such as avoiding and obliging (Chua \& Gudykunst, 1987; Oetzel et al., 2000; Ting-Toomey et al., 2001). Rahim et al. (1992) support this by reporting the increased use of nonconfrontational management styles, such as obliging, in organizations. Based on these findings the following is hypothesized:

$\mathrm{H} 2$ : Individuals will less frequently use a non-confrontational style of conflict management in their personal life than they will in their 
organization(s).

Individuals in low-context cultures tend to use direct, explicit, and open communication resulting in solution-orientation styles (Chua \& Gudykunst, 1987; TingToomey et al., 2001). Based on these findings it is hypothesized:

H3: Individuals will more frequently use the collaborating conflict management style of conflict within their personal lives than they will in their organization(s).

Additionally, Antonioni (1998) establishes support for the five personality factors, (extraversion-introversion, agreeableness-antagonism, conscientiousness-undisciplined, openness-closeness, and neuroticism-emotional stability) contribution to choosing a conflict management style. Agreeableness, extraversion, and conscientiousness positively correlated with the use of the integration style. Through studying the OCCI and the five personality traits, Moberg (1998) found nonconfrontation to be positively related to consciousness and negatively related to openness. The use of solution orientation was found to be positively related to openness, conscientiousness, and agreeableness. The use of control strategies was positively related to extraversion and negatively related to agreeableness.

Introverts tend to avoid conflict or collaboration. Others who desire control usually implement competition or assertiveness (Kilmann \& Thomas, 1977). Although conflict situations encompass numerous areas and details, a correspondence exists among personality traits and conflict management styles within different situations (Sternberg \& Dobson, 1987).

The previous research supports the relationships between the personality factors 
and conflict management styles. However, research has not considered how personality factors relate to variability between contexts. Since there is not direct evidence, the following research question is asked:

RQ1: Which personality types would be related to the greatest variability in the use of conflict management styles between personal lives and organization(s)? 


\section{Chapter 2}

Method

\section{Participants}

The sample consisted of 126 participants who responded positively when asked if they held full time employment. Approximately half (60) participants were recruited through an off campus master's programs. The remaining half (66) were recruited through a network sample. Fifty-two percent (65) of the sample were males and 48 percent (59) were females. Forty-four percent (55) had been at their current job for 1 to 5 years, 18 percent (23) had been there for 6 to10 years, 17 percent (21) had been there for 11 to 5 years, and 21 percent (26) had been at their current job for over 16 years. Twenty-six percent (33) had an associate's degree or less education, 22 percent (28) had a bachelors degree and 52 percent (65) had at least some post-bachelor work. Fifty-five percent (69) reported having had some form of conflict management training in the organization or in their personal lives. The participants completed two copies of the OCCI and the Extraversion, Neuroticism and Psychoticism scale (Eysenck \& Eysenck, 1985; Putnam \& Wilson, 1982). The first version of the Organizational Communication Conflict Instrument (Putnam \& Wilson, 1982) instructed participants to complete the measure based on a specific conflict with a friend who is a not a co-worker. The second version of the OCCI instructed participants to complete the measure based on a specific conflict with a friend who is a coworker (Putnam \& Wilson, 1982). The Extraversion, Neuroticism, Psychoticism (ENP) scale (Eysenck \& Eysenck, 1985), serves as a general measure of personality. Participants also provided general demographic information.

\section{Instruments}




\section{Organizational Communication Conflict Instrument.}

Putnam and Wilson's (1982) Organizational Communication Conflict Instrument (OCCI) scale assesses strategies for managing conflict in organizations. The OCCI was developed as an instrument focused on communicative behaviors with the understanding that "conflict strategies are those communicative behaviors, both verbal and nonverbal, that provide a means for handling conflict" and "a particular conflict strategy is largely governed by situational rather than personality constraints" (Putnam \& Wilson, p. 633). The OCCI consists of 30 questions with responses measured on a seven point Likert scales assessing three conflict styles of solution-orientation, non-confrontational, and control (Putnam \& Wilson).

The OCCI focuses on the situation instead of personality constraints in an individual's choice of particular conflict strategies. These situations include the nature of the conflict, the relationship between the participants, the structure of the organization, and the environment (Putnam \& Wilson, 1982).

The OCCI has been shown to be reliable and to possess construct and predictive validity (Witteman, 1992). Through studying situational perceptions, conflict management styles, and initiation of conflict, Witteman found the OCCI to have alpha reliability coefficients ranging from .88 to .97 . The OCCI was also subject to test-retest reliability and was found to be as reliable as other conflict measurements during a study of cultural influence on conflict management styles (Chua \& Gudykunst, 1987). For the present investigation the overall instrument was found to have alpha coefficients at .75.76 , with controlling at .83-.80, nonconfrontational at .88-.90, and solution-orientation at $.87-.83$ (see Table 1). 


\section{Extraversion, Neuroticism, and Psychoticism}

Eysenck and Eysenck (1985) developed the Big Three extraversion, neuroticism, and psychoticism (ENP) scale to measure personality. The psychoticism scale was revised in 1985 by Eysenck, Eysenck, and Barrett. The ENP consists of 10 questions for each of the three personality types and requires participants to respond using a three point Likert scale. Cronbach alphas for the scale have ranged from .78 to .82 for extraversion, .80 to .86 for neuroticism and .62 to .76 for psychoticism (Valencic, McCroskey, \& Richmond, 2001). The present study found the ENP to have alpha coefficients of .75 for extraversion, .85 for neuroticism, and .57 for psychoticism (see Table 2).

Data analysis

A difference score was created on each conflict management style by subtracting the OCCI score from their personal life from the OCCI score in the organization. A t test and means analysis was run on each conflict management style to determine the difference between conflict management styles in one's personal life as opposed to one's organizational life. A Pearson's correlation was run on the conflict management styles and the ENP. 


\section{Chapter 3}

Results

Hypothesis one forwarded that individuals will more frequently in use the controlling style of conflict management in their personal lives than they will in their organization(s). Result of a paired $t$ test did not support the hypothesis $(\underline{\mathrm{t}}(126)=.49 ; \underline{\mathrm{p}}>$ $.05)$. The mean for the use of the controlling style in one's personal life was 30.68 and the mean for the organization was 30.50 (see Table 1)

Hypothesis two forwarded that individual's will less frequently use a nonconfrontational style of conflict management in their personal lives than they will in their organization(s). Result of a paired $t$ test did not support the hypothesis $(\underline{\mathrm{t}}(126)=-.27 ; \underline{\mathrm{p}}>$ $.05)$. The mean for the use of the nonconfrontational style in one's personal life was 52.78 and the mean for the organization was 52.98 (See Table 1).

Hypothesis three forwarded that individuals will more frequently use solution orientation conflict management techniques within their personal lives than they will in their organization(s). Result of a paired $t$ test did not support the hypothesis $(\underline{t}(126)=-$ $.06 ; p>.05)$. The mean for the use of the solution orientation style in one's personal life was 38.48 and the mean for the organization was 38.52 (see Table 1).

Research question one was concerned with which personality types would be related to the greatest variability in conflict management styles between personal lives and organizations. Results of a Pearson correlation failed to report any significant relationships between the three personality types and conflict difference scores (see Table 2). 
Post Hoc Analysis

Simple correlations were run between Extraversion, Neuroticism and Psychoticism and the three conflict management styles in the different contexts to see if relationships exist between personality and conflict management styles. The only relationships to reach significance was the Nonconfrontational style within the organization with Extraversion $(r=.25)$ and Neuroticism $(r=-.21)$. Solution Orientation within the organization reached significance with Extraversion $(r=-.10)$ (see Table 3). 


\section{Chapter 4}

\section{Discussion}

The purpose of the study was to look at how individuals deal with conflict in different contexts. The study looked particularly at how individuals deal with conflict, with a friend in their personal life as opposed to how they deal with conflict with a friend in their organization. Also addressed was the relationship between the Big Three personality types and differences in the use of conflict management styles across contexts.

In order to analyze differences in ones conflict management style a difference score was created for each conflict management style. Subtracting ones score for their organization from their personal life created this score. A positive score meant the individual utilized the style more in their personal life then the workplace and a negative score means one utilized the style more in their workplace then in their personal life.

Hypothesis one suggested that individuals would utilize a controlling style of conflict management more often in their personal lives than in the organization. Hypothesis one was not supported. An individual's controlling conflict management style did not vary among dealing with a conflict with a friend in one's personal life as opposed to the organization.

Hypothesis two suggested that individuals would utilize a nonconfrontational style of conflict management more often in the organization than in their personal lives. Hypothesis two was also not supported. An individual's nonconfrontational conflict management style did not vary among dealing with a conflict with a friend in one's personal life as opposed to the organization. 
Hypothesis three suggested the findings would indicate that individuals would utilize a solution orientation style of conflict management more often in their personal lives than in the organization. Hypothesis three was not supported. An individual's solution orientation conflict management style did not vary among dealing with a conflict with a friend in one's personal life as opposed to the organization.

Research question one asked which personality types would be related to variability in one's conflict management styles based on situational factors. While none of the Big Three personality variables had a significant relationship with the conflict difference score the relationship with Neuroticism and the nonconfrontational difference score, was approaching significance. However, even if this relationship was found to be significant it would be significant it would have been a small relationship accounting for approximately four percent of the variance.

While the results of the investigation failed to yield any significant relationships, the interesting finding is the lack of variability in conflict styles. The means for the three OCCI subscales across contexts are nearly identical. This coupled with the lack of significance in the paired $t$ test indicates that the way people manage conflict may be stable across situations. These findings contradict Putnam and Wilson's (1982) assertion that particular situations drive conflict management styles, not personality. Conversely, the findings support Canary et al.'s (2001) argument that people tend to continue to use one conflict management method.

A second implication might be that individuals view their friends as part of a high context culture. This is indicated in the lack of conflict management style changes that took place in an individual. The findings imply that friends in all situations have a 
shared reality, rituals, culture, rules and roles, which indicates a high context culture (Infante et al., 1994; Pacanowsky \& Trujillo, 1983).

The first limitation to the study was that the sampling technique was not consistent among participants. Half of the participants completed the survey over a twoweek interval. The other half of the participants completed the survey at one time. When the data collection varies this can result in different interpretation of the data among the different participants.

The second limitation was that the participants who completed the survey in two parts might have been hindered in their ability to think of the subtle, yet important, differences in handling conflict in the two situations. The other participants had the opportunity to evaluate their conflict management styles in their personal life and then immediately evaluate their conflict management styles in the organization. This allowed the participant to be more attuned to the differences that might be present in the two contexts. The means for the sample who completed the survey at one time were not significantly different, but there were slight differences between their OCCI scores. There is a possibility given a larger sample size that these differences might reach statistical significance.

A third limitation to the study might be that we are asking for two ingroup situations. Friends are a part of one's ingroup and an individual's conflict management style might be the same when dealing with particular levels of people within ones ingroup. Differences in one's conflict management styles might only emerge when questioning ingroup verses outgroup contexts, such as family verses organizational. This assertion finds support through the work of Graen and colleagues on Leader Member 
Exchange Theory. This theory explains that superiors interact differently with subordinates based on whether or not the subordinate is considered to be in their ingroup or outgroup (Graen, Novak, \& Sommerkamp, 1982).

Furthermore, the study might have been limited by the use of the term conflict in the directions and the survey. To some, conflict is a concept that implies irresolvable, extremely stressful, or milestone events. Some participants indicated they do not have conflict with any of their friends. If the wording were to be changed to disagreement, participants might have more readily thought of a situation and could remember how the situation was handled, and not have limited themselves to a "conflict" that fit their definition. This also could have been avoided if a definition of conflict was provided for the participants.

The study of conflict can be taken in many different directions. First, conflict in different contexts needs to be looked at to clarify and determine when and with whom do people utilize different conflict styles. Are differences found only when looking at ingroups verses outgroups or are there times when differences are found between two different ingroups?

Next, if styles are unchanging within an individual, then what is this indicating. Are conflict management styles a reflection of one's personality and temperament? This would seem to be in contrast to Putnam and Wilson's (1982) drive in developing the OCCI. Is conflict management style an extension of one's temperament, indicating that one's conflict management style will be consistent in all situations?

If individuals do not change their conflict management styles, the next step would be to research the results of the different styles used in different contexts. Is it beneficial 
for individuals to maintain one style in all situations, or do individuals receive different results depending on the situation in which they use the style? This finding would enhance one's ability to better explain and create an understanding for others as to why they might wish to develop multiple management styles in order to increase their chances of a successful outcome. 


\section{Reference}

Antonioni, D. (1998). Relationship between the big five personality factors and conflict management styles. International Journal of Conflict Management, 9,336-355.

Canary, D. J., Coach, W. R., \& Serape, R. T. (2001). A competence-based approach to examining interpersonal conflict. Communication Research, 28, 79-104.

Canary, D. J., \& Spitzberg, B. H. (1987). Appropriateness and effectiveness perceptions of conflict strategies. Human Communication Research, 14, 93-118.

Chua, E. G., \& Gudykunst, W. B. (1987). Conflict resolution styles in low-and highcontext cultures. Communication Research Reports, 4, 32-37.

Drory, A., \& Ritov, I. (1997). Effects of work experience and opponents power on conflict management styles. International Journal of Conflict Management, 8, $148-161$.

Eysenck, H. J. \& Eysenck, S. B. G. (1985). Personality and individual differences: A natural science approach. New York: Plenum.

Eysenck, S. B. G., Eysenck, H. J., \& Barrett, P. (1985). A revised version of the psychoticism scale. Personality and Individual Differences, 6, 21-29.

Graen, G., Novak, M. A., \& Sommerkamp, P. (1982). The effects of leader-member exchange and job design on productivity and satisfaction: Testing a dual attachment model. Organizational Behavior and Human Performance, 30, 109131.

Infante, D. A., Myers, S. A., Buerkel, R. A., (1994). Argument and verbal aggression in constructive and destructive family and organization disagreements. Western 
Journal of Communication, 58, 73-84.

Jameson, J. K. (1999). Toward a comprehensive model for the assessment and management of intraorgaziational conflict: Developing the framework. International Journal of Conflict Management, 10, 268-294.

Kilmann, R. H., \& Thomas, K. W. (1977). Developing a forced-choice measure of conflict-handling behavior: The "mode" instrument. Educational and Psychology Measurement, 37, 309-325.

Knapp, M. L., Putman, L. L., \& Davis, L. L. (1988). Measuring interpersonal conflict in organizations: Where so we go from here?. Management Communication Quarterly, 3, 414-429.

Meyer, J. P., Gemmell, J. M., \& Irving, G. (1997). Evaluating the management of interpersonal conflict in organizations: A factor-analytic study of outcome criteria. Canadian Journal of Administrative Sciences, 14, 1-13.

Millar, F. E., Rogers, E., \& Bavelas, J. B. (1984). Identifying patterns of verbal conflict in interpersonal dynamics. Western Journal of Speech Communication, 48, 231246.

Moberg, P. J. (1998). Predicting conflict strategy with personality traits: Incremental validity and the five factor model. International Journal of Conflict Management, 9, 258-285.

Nicotera, A. M. (1994). The use of multiple approaches to conflict: A study of sequences. Human Communication Research, 20, 592-621.

Oetzel, J. G. (1998). Explaining individual communication processes in homogeneous and heterogeneous groups through individualism: Collectivism and self-construal. 
Human Communication Research, 25, 202-224.

Oetzel,, J. G., Ting-Toomey, S., Yokochi, Y., Masumoto, T., \& Takai, J. (2000). A typology of facework behaviors in conflict with best friend and relative strangers. Communication Quarterly, 48, 397-479.

Ohbuchi, K., \& Fukushima, O. (1997). Personality and interpersonal conflict: Aggressiveness, self-monitoring, and situational variables. International Journal of Conflict Management, 8, 99-113.

Pacanowsky, M. E. \& Trujillo, N. (1983). Organizational communication as culture performance. Communication Monographs, 50, 126-147.

Putnam, L. L. (1988). Communication and interpersonal conflict in organizations. Management Communication Quarterly, 3, 293-301.

Putnam, L. L., \& Wilson, C. E. (1982). Communicative strategies in organizational conflicts: Reliability and validity of a measurement scale. Communication Yearbook, 6, 629-652.

Rahim, M. A., Garrett, J. E., \& Buntzman, (1992). Ethics of managing interpersonal conflict in organizations. Journal of Business Ethics, 11, 423. Retrieved February 4, 2001, from Proquest database.

Ritov, I., \& Drory, A. (1996). Ambiguity and conflict management strategy. International Journal of Conflict Management, 7,139-155.

Sternberg, R. J., \& Dobson, D. M. (1987). Resolving interpersonal conflicts: An analysis of stylistic consistency. Journal of Personality and Social Psychology, 52, 794812.

Thomas, K. W. (1976). Conflict and conflict management. In M. B. Dunnette (Ed.), 
Handbook of industrial and organizational psychology (pp. 889-935). Chicago: Rand McNally.

Ting-Toomey, S., Oetzel, J. G., \& Yee-Jung, K. (2001). Self-construal types and conflict management styles. Communication Reports, 14, 87-104.

Valencic, K. M., McCroskey, J. C., \& Richmond, V. P. (2001). The effect of teacher temperament on students' perceptions of teacher communication behavior.

Walton, R.E. (1987). Managing conflict. ( $2^{\text {nd }}$ Edition).Reading, MA: Addison-Wesley.

Witteman, H. (1992). Analyzing interpersonal conflict: Nature of awareness, type of initiating event, situational perceptions, and management style. Western Journal of Communication, 56, 248-280. 
Table 1: Descriptive Statistics for Conflict Style Measures and t-value for comparison across contexts.

\begin{tabular}{|l|c|c|c|}
\hline & Personal & Organizational & t-value \\
\hline Nonconfrontational & $52.78(9.92)$ & $52.98(10.81)$ & -.27 \\
& $\alpha=.88$ & $\alpha=.90$ & .49 \\
\hline Controlling & $30.68(6.28)$ & $30.50(6.16)$ & \\
& $\alpha=.83$ & $\alpha=.80$ & -.06 \\
\hline Solution-Orientation & $38.48(7.86)$ & $38.52(7.27)$ & -.06 \\
& $\alpha=.87$ & $\alpha=.83$ & \\
\hline OCCI Total & $121.90(12.62)$ & $122.00(12.56)$ & $\alpha=.76$ \\
& $\alpha=.75$ & & \\
\hline
\end{tabular}

Note: $*$ indicates $\mathrm{p}<.05$ 
Table 2 : Descriptive Statistics for ENP and correlations between conflict management different scores

\begin{tabular}{|l|c|c|c|c|}
\hline Extraversion & $\begin{array}{c}\text { Descriptive } \\
\text { Statistics }\end{array}$ & $\begin{array}{c}\text { Nonconfrontational } \\
\text { Difference } \\
\alpha=.75\end{array}$ & $\begin{array}{c}\text { Controlling } \\
\text { Difference }\end{array}$ & $\begin{array}{c}\text { Solution- } \\
\text { Orientation } \\
\text { Difference }\end{array}$ \\
\hline Neuroticism & $\begin{array}{c}17.50(4.80) \\
\alpha=.85\end{array}$ & -.13 & -.03 & .09 \\
\hline Psychoticism & $\begin{array}{c}19.62(2.09) \\
\alpha=.57\end{array}$ & .08 & -.11 & -.02 \\
\hline
\end{tabular}

Note: $*$ indicates $\mathrm{p}<.05$ 
Table 3: Correlations between ENP and the subscales of the OCCI

\begin{tabular}{|l|l|l|l|}
\hline & Extraversion & Neuroticism & Psychoticism \\
\hline $\begin{array}{l}\text { Nonconfrontational } \\
\text { Personal }\end{array}$ & $\mathrm{r}=.145$ & $\mathrm{r}=-.072$ & $\mathrm{r}=-.045$ \\
\hline $\begin{array}{l}\text { Nonconfrontational } \\
\text { Work }\end{array}$ & $\mathrm{r}=.252^{*}$ & $\mathrm{r}=-.212^{*}$ & $\mathrm{r}=-.107$ \\
\hline Controlling Personal & $\mathrm{r}=.011$ & $\mathrm{r}=-.158$ & $\mathrm{r}=-.087$ \\
\hline Controlling Work & $\mathrm{r}=.034$ & $\mathrm{r}=.-.084$ & $\mathrm{r}=-.199$ \\
\hline $\begin{array}{l}\text { Solution-Orientation } \\
\text { Personal }\end{array}$ & $\mathrm{r}=-.072$ & $\mathrm{r}=-.078$ & $\mathrm{r}=-.109$ \\
\hline $\begin{array}{l}\text { Solution-Orientation } \\
\text { Work }\end{array}$ & $\mathrm{r}=-.103^{*}$ & $\mathrm{r}=-.069$ & $\mathrm{r}=-.159$ \\
\hline
\end{tabular}

Note: * indicates a $\mathrm{p}<.05$ 